\title{
Evaluation and Impact of ASPIRE: An Interactive Tobacco Prevention Curriculum among University Students in India
}

\author{
Gayatri Vishwakarma ${ }^{1}$, Sohini Singh ${ }^{2} \quad$ Salma K Marani ${ }^{3} \quad$ Ashish Arya $^{3} \quad$ Karen Calabro $^{4}$ \\ Garima Gupta ${ }^{5}$ Anurag Mehta ${ }^{5}$ Alexander V. ${ }^{6}$
}

${ }^{1}$ Indian Spinal Injuries Centre, New Delhi, India

2Department of Biotechnology, Amity University, Noida, Uttar Pradesh, India

${ }^{3}$ Youth and Family Cancer Prevention Program, University of Texas, M D Anderson Cancer Center, Houston, Texas, United States

${ }^{4}$ Department of Behavioral Sciences, University of Texas, M D Anderson Cancer Center, Houston, Texas, United States

\author{
Address for correspondence Gayatri Vishwakarma, PhD, \\ Head-Biostatistics, Indian Spinal Injuries Centre, New Delhi, India \\ (e-mail: gayatri.singh.v@gmail.com). \\ ${ }^{5}$ Rajiv Gandhi Cancer Institute and Research Centre, New Delhi, \\ India \\ ${ }^{6}$ Youth and Family Cancer Prevention Program, University of Texas, \\ MD Anderson Cancer Center, Houston, Texas, United States
}

South Asian J Cancer 2021;10:144-150.

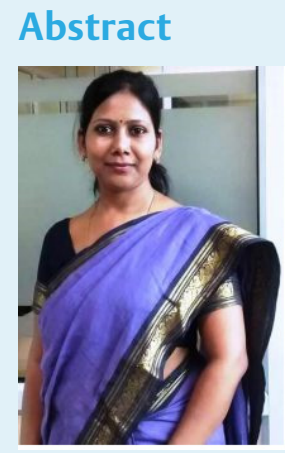

Gayatri Vishwakarma

Keywords

- A Smoking Prevention Interactive Experience (ASPIRE)

- curiosity

- smoking

- knowledge

- prevention
Online education approach provides innovative opportunities for engaging youths. Web-based, multimedia smoking prevention programs have been tested in high-income countries; however, efficacy of such programs is not well-investigated in low- and middle-income countries. The aim of this study was to evaluate the impact of A Smoking Prevention Interactive Experience (ASPIRE), an interactive tobacco prevention curriculum, among university students in India.

A single-subject cohort study where each subject serves as their own control was conducted among university student participants engaged in ASPIRE, 60 minutes per week for five consecutive weeks during July to August of 2019. Assessments were conducted at baseline and immediately after exposure to ASPIRE. To evaluate the program, a structured instrument was specifically designed to measure the outcomes. A total of 103 university students participated voluntarily. Average age of the participants was $18.3 \pm 0.9$ ranging from 17 to 20 years. Eighteen percent of students were curious to know about the various smoking products. More males were more susceptible to cigarette smoking as compared to females. The majority of participants felt that ASPIRE was culturally appropriate for young adults in India, but a modified version targeted toward Indian youth would be more acceptable. Pre- to postintervention knowledge of tobacco-related hazards increased from 70 to $97 \%(p<0.001)$.

ASPIRE, a multimedia interactive program, demonstrated its considerable potential to discourage smoking initiation among Indian youth.

\section{Introduction}

\section{Prevalence and problem in India}

Smoking in public places was prohibited nationwide from October 2008. According to the World Health Organisation,

DOI https://doi.org/10.1055/s-0041-1731900 ISSN 2278-330X

How to cite this article: Vishwakarma G, Singh S, Marani S. K, et al. Evaluation and Impact of ASPIRE: An Interactive Tobacco Prevention Curriculum, among University Students in India South Asian J Cancer 2021;10(3):144-150.
$12 \%$ of the world's smokers reside in India and more than one million people die every year due to tobacco-related illnesses, including malignant neoplasms. ${ }^{1}$ Many studies and reports confirm that an estimated 120 million Indian adults smoked in 2010. Mostly the smoked tobacco is in the form

\section{(c) 2021. MedIntel Services Pvt Ltd.}

This is an open access article published by Thieme under the terms of the Creative Commons Attribution-NonDerivative-NonCommercial-License, permitting copying and reproduction so long as the original work is given appropriate credit. Contents may not be used for commercial purposes, or adapted, remixed, transformed or built upon. (https://creativecommons.org/licenses/by-nc-nd/4.0/).

Thieme Medical and Scientific Publishers Private Ltd A-12, Second Floor, Sector -2, NOIDA -201301, India 
of bidis, small locally made cigarettes with tobacco wrapped inside a Tendu leaf. In 2010, smoking caused about 10 lakh deaths or $10 \%$ of all deaths in India. ${ }^{2}$ Seventy percent of dead were in age of 30 to 69 years. The Times of India (2015) says "smoking dips $10 \%$ in 2 years in India but women smokers up sharply. Cigarette consumption falling in India but women smokers have more than doubled in last 2-3 decades. ${ }^{3}$ "

TechNavio's reported that the electronic cigarette (e-cigarette) market in India will grow at a compound annual growth rate of $63.4 \%$ over the period 2013 to 2018; thus, growth prospects of the e-cigarette are high. ${ }^{4}$ Tobacco companies are aggressively promoting use of differently flavored e-cigarettes. Flavor reduces the aversive smell of tobacco and companies mislead consumers, particularly young adults, by marketing e-cigarettes as safer than-smoking conventional cigarettes. The market forecast is based on the understanding that e-cigarette sales during the forecast period may not be affected by the sociopolitical and legal dynamics in the country.

Over $11 \%$ of 6.4 million deaths worldwide was caused by smoking in 2015 and $52.2 \%$ of them took place in China, India, United States, and Russia, according to the latest estimates in the global burden of disease study published in The Lancet. ${ }^{5}$ India has $11.2 \%$ of the world's total smokers. ${ }^{6}$ Although the deleterious effects of tobacco addiction are well-known, its consumption has not gone down in India considerably. As per data, tobacco causes one death every 6 seconds. In India, smokers are more likely to become addicted if they start using tobacco during their teenage years. Because of nicotine addiction, about three out of four teen smokers end up smoking into adulthood, even if they intend to quit after a few years. ${ }^{7}$ Youth, who begin smoking at an early age, have a high probability of death from tobacco-related disease during adulthood. Smoking has become a status symbol among youth. ${ }^{8}$ Large proportions of adolescents in Asian countries, especially males, initiate smoking as a part of "normal behavior" associated with their transition to adulthood. Albeit, the rising trend of tobacco use among the girls shown in recent studies should not be ignored. ${ }^{9}$

\section{Background and outreach of ASPIRE}

The University of Texas MD Anderson Cancer Center provides a school-based cancer prevention and tobacco control program, ASPIRE. ASPIRE (abbreviation for A Smoking Prevention Interactive Experience) is an online program that informs adolescents about risks of tobacco products and reinforces tobacco-free norms. ASPIRE is a multimedia interactive curriculum for smoking prevention and cessation for middleand high-school students. It was tested as a randomized trial in 16 Houston Independent School District high schools. ${ }^{10,11}$ It is available in English and Spanish and is disseminated to national and international organizations through grassroots marketing, social media, and public relations. ASPIRE is posted on the National Cancer Institute's website as part of the registry of "Research-tested intervention programs." The program was favorably evaluated by the Cochrane Review. ${ }^{12}$

On the national level, hundreds of schools have adopted and used ASPIRE as a curriculum. ASPIRE is a self-administered program, includes five modules, and takes up to 4 hours to complete. Participants who earn the ASPIRE certificate are considered ASPIRE "graduates." In January 2018, a new version of ASPIRE was launched and includes five modules and takes up to 4 hours to complete. Participants who earn the ASPIRE certificate are considered ASPIRE "graduates." This new version retains the theoretical underpinnings of the previous version and it includes contents on new and emerging products such as e-cigarettes, heat-not-burnt forms (e.g., IQOS), hookah (water-pipe), chewing tobacco, and marijuana. Currently, over 40,000 students have graduated from ASPIRE in the United States and over 1500 students from Romania, Columbia, Mexico, and Lebanon. Our colleagues from Romania have successfully replicated the impact of ASPIRE in a randomized controlled trial among local youth. ${ }^{13}$ Authors decided to conduct a preliminary study of the new version of ASPIRE in India.

\section{Methodology}

The study used a single-subject cohort design where each subject serves as their own control. This was a longitudinal pre-post study in which the individuals were the unit of design, allocation, and analysis. The design strategy was controlled for many interindividual confounding variables as well as required a smaller sample size. A total of 119 participants (aged 17-18 years) were recruited from Amity University in India. Sample size justification is based on the primary endpoint of feasibility, that is, knowledge about health, environmental consequences of tobacco, and skills to resist tobacco and nicotine products. The primary feasibility criterion was comparison of pre- and postintervention knowledge scores. To estimate detectable differences, we used what Cohen refers to as an "Effect Size Index" in which the detectable difference is given in terms of the population standard deviation units. ${ }^{14}$ The following calculation gives a range of effect sizes assuming at least $80 \%$ power to detect significant differences from baseline to posttest at the 0.05 level. Effect sizes of this magnitude are considered reasonable for a feasibility study. Using a paired sample $t$-test with a 0.05 two-sided significance level, a sample size of 100 students has power of at least $80 \%$ to detect effect sizes of $0.4,0.5$, and 0.6 .

Assessments were conducted preexposure to ASPIRE and immediately at postexposure. University student participants were engaged in ASPIRE, 60 minutes per week for 5 consecutive weeks during July to August, 2019. Students accessed the interactive interface individually using a desktop computer provided in a computer laboratory in the campus.

Criteria for inclusion in the study were students aged 17 to 20 years of age regardless of gender and tobacco use status.

Participants were informed about the goals, benefits, risks, and time commitment required prior to the beginning of the study. Students aged 17 to 20 years of age were recruited; parental informed consent and participant assent for those less than 18 years of age and participant consent for those aged more than 18 years were obtained. To evaluate the program, a structured instrument was specifically designed to measure the outcomes. A baseline questionnaire was administered 1 week before taking the ASPIRE curriculum. 
Immediately after working through the curriculum, the ASPIRE posttest appears automatically along with the other measures identical to the pretest items. The web-based questionnaires were completed in the computer labs during one teaching hour under the supervision of trained field assistants unknown to the student. Neither teachers nor university staff were present in the classrooms during the evaluations.

\section{Analytical Plan}

Sociodemographic variables and tobacco use patterns including ever use, past 30-day use, and peer and home smoking were summarized with descriptive statistics including frequency distributions for categorical variables and mean and standard deviation for continuous variables. Effective use is the amount of exposure to ASPIRE measured by the number of modules completed of which progress can be tracked in real-time. The percent of participants with effective use (100\% completion of the five modules and assessments) was computed.

Cultural acceptability and Appeal of ASPIRE: Specifically, we were interested in knowing how young Indian students responded to ASPIRE. Cultural acceptability and appeal of ASPIRE also measured the motivational appeal and educational value of ASPIRE as rated by Indian students.

Curiosity scale: Survey items were designed to determine participant curiosity about tobacco products including cigarettes, smokeless tobacco, electronics vapor product, or hookah/huqqa pipe. Items were rated using a 5-point Likert-scale and higher scores indicated greater endorsement of the statement. Results were summarized using frequency distributions and percentages. ${ }^{15}$

Cognitive susceptibility: Respondents were considered susceptible if they failed to exhibit a firm commitment not to smoke during the next year and if offered a cigarette by a friend. The percent of nontobacco and nicotine users who were susceptible was computed at baseline and postexposure to ASPIRE. McNemar's tests of association determined whether there was a significant reduction in susceptibility from pre- to postexposure to ASPIRE.
Knowledge: Specific items comprising knowledge covered in the ASPIRE modules were computed as a scale. A binary variable was created to indicate whether participants score $70 \%$ or higher on the pre- and posttest items pertaining to knowledge. An exact McNemar's test was used to determine if there was a statistically significant increase from preto postintervention knowledge of modules in ASPIRE.

\section{Results}

Participant characteristics: A total of 145 undergraduate university students were recruited for this study. Informed consents were received from 103 students for voluntarily participation. Baseline survey and postexposure survey were completed by 103 students. Average age of the participants was $18.3 \pm 0.9$ years ranging from 17 to 20 years, whereas onset age of smoking was ranging from 4 to 12 years. Of these students $46.6 \%$ were male and $87.4 \%$ of the students were from Hindu origin. Around 68\% students were living with their family ( - Table 1 ). Baseline tobacco and nicotine product use by participants were depicted in - Table 2.

Baseline tobacco and nicotine product use: A total of 19 out of 103 students (18.4\%) reported ever use of cigarettes and $11.7 \%$ students had tried smokeless tobacco (dip, chew, PAAN/ KHAINI, snuff, ash, snus, etc.). Past 30-day use was 10.7 and $2.9 \%$. The reason for smoking given by $36 \%$ of smokers was "to relieve stress/tension" and for $64 \%$ smoking was "Status symbol/good time with friends." Students had also tried electronic cigarettes and hookah.

Curiosity about tobacco use: Results showed that $18 \%$ students were somewhat to very curious to know how a cigarette, smokeless tobacco products, electronics vapor product, or hookah/huqqa pipe tasted, whereas $15 \%$ students were somewhat curious to know how these products feel and $14 \%$ participants wanted to know what is special about tobacco smoking, smokeless, electronic vapor products, or hookah/huqqa pipes.

Measures: In order to evaluate the impact of ASPIRE, the following measures were utilized:

\begin{tabular}{|l|l|}
\hline Measures/items & Description \\
\hline Knowledge about tobacco & $\begin{array}{l}26 \text { items, multiple-choice developed specifically for ASPIRE inquiring about nicotine addic- } \\
\text { tion, health risks of tobacco products, environmental impact, and financial costs. The items } \\
\text { are programed to be assessed pre-ASPIRE and immediately after its completion on the } \\
\text { desktop computer }\end{array}$ \\
\hline Demographics & Survey of age, gender, current student residence, and faith group affiliation \\
\hline Tobacco use & $\begin{array}{l}\text { Items of the survey about patterns about tobacco smoking, smokeless tobacco, hookah, } \\
\text { electronic cigarettes: when started using, frequency of use, current use. }\end{array}$ \\
\hline $\begin{array}{l}\text { Cognitive susceptibility to using tobacco } \\
\text { products }\end{array}$ & $\begin{array}{l}\text { Susceptibility items on the survey about tobacco smoking, smokeless tobacco, hookah, } \\
\text { electronic cigarettes }\end{array}$ \\
\hline Curiosity about using tobacco products & $\begin{array}{l}\text { Survey items were designed to determine participant curiosity about tobacco products } \\
\text { including cigarettes, smokeless tobacco, electronics vapor product, or hookah/huqqa pipe. } \\
\text { Items were rated using a 5-point Likert-scale }\end{array}$ \\
\hline Cultural acceptability & $\begin{array}{l}\text { Survey items of program participants' perceptions about the acceptability of the ASPIRE } \\
\text { program "as it is" or whether modifications are required for students in India. These items } \\
\text { were developed for this project }\end{array}$ \\
\hline Participant advocacy & $\begin{array}{l}\text { Items related to initiating the topic of quitting with friends and family, whether helped and } \\
\text { supported parents and friends quit using items developed for this project }\end{array}$ \\
\hline
\end{tabular}


Table 1 Participants characteristics at baseline (preexposure)

\begin{tabular}{|c|c|c|}
\hline \multirow[t]{2}{*}{ Variable } & \multicolumn{2}{|c|}{$(n=103)$} \\
\hline & $n$ & $(\%)$ \\
\hline \multicolumn{3}{|l|}{ Gender } \\
\hline Female & 48 & 46.6 \\
\hline Male & 55 & 53.4 \\
\hline \multicolumn{3}{|l|}{ Religion } \\
\hline Hinduism & 90 & 87.4 \\
\hline Sikhism & 3 & 2.9 \\
\hline Islam & 2 & 1.9 \\
\hline Christianity & 4 & 3.9 \\
\hline Jainism & 3 & 2.9 \\
\hline No religion & 1 & 1.0 \\
\hline \multicolumn{3}{|l|}{ Living with/in } \\
\hline Family & 70 & 68.0 \\
\hline Hostel & 12 & 11.7 \\
\hline Paying guest & 10 & 9.7 \\
\hline Friends & 6 & 5.8 \\
\hline Local guardian & 5 & 4.8 \\
\hline \multicolumn{3}{|c|}{ Other (NA, Al, other) } \\
\hline \multicolumn{3}{|c|}{ Does anyone at home use tobacco? } \\
\hline Yes & 23 & 22.3 \\
\hline \multicolumn{3}{|c|}{ Close friends use tobacco? } \\
\hline$<3$ & 55 & 53.4 \\
\hline$\geq 3$ & 48 & 46.6 \\
\hline
\end{tabular}

\section{Baseline nonuser: Susceptibility to Tobacco and Nicotine Products}

The susceptibility measure was computed using the algorithm proposed by Pierce et al. ${ }^{16,17}$ Respondents are considered susceptible if they fail to exhibit a firm commitment not to smoke during the next year and if offered a cigarette by a friend. Males were more susceptible to cigarette smoking compared to females, although susceptibility to other tobacco products was similar between males and females. Chi-square tests did not show statistical differences at $p<0.05$ level ( - Table 3 ).

\section{Postexposure to ASPIRE}

Cultural acceptance of ASPIRE: Cultural acceptance of ASPIRE was measured on a scale of 1 (strongly disagree) to 5 (strongly agree). The majority of participants felt that ASPIRE was culturally appropriate for young adults in India but an adapted version targeted toward Indian youth would be more acceptable ( $\rightarrow$ Table 4 ).

\section{Postexposure Motivational Appeal and Educational Value of Aspire}

Participants who completed the program were asked to respond on the following questions pertaining to motivational appeal, educational value, and behavior modification.
The majority of ASPIRE participants reported an increased knowledge of tobacco hazards, an intention to adopt a tobacco-free lifestyle, and a willingness to share ASPIRE with others ( - Table 5 ).

Participant advocacy: Students who completed ASPIRE were asked if they had close family or friends who used tobacco. Approximately, 54\% responded "Yes." The majority responded high concern and desire to help ( - Table 6 ).

Pre- to postexposure knowledge: A total of 103 participants completed the pre- and postexposure tests. After working through the ASPIRE curriculum, there was a significant increase in participants who scored $70 \%$ or higher on posttest knowledge about the health, environmental, and financial consequences of using tobacco and nicotine products. Pre- to postintervention knowledge increased from $70 \%$ who scored above $70 \%$ at pretest to $97 \%$ who scored $70 \%$ or higher at posttest. An exact McNemar's test determined that this was a statistically significant increase $(p<0.001)$. - Fig. 1 describes change in knowledge from pre- to postexposure. Males scored higher than females on pre- and posttests.

\section{Postexposure Change in Cognitive Susceptibility to Tobacco Use}

Table 7 describes the change in susceptibility from preto postexposure to tobacco and nicotine products. Among participants who were susceptible at baseline the majority became nonsusceptible at postexposure ranging from 78 to $100 \%$ for different products ( - Table 7 ). Among those who were nonsusceptible at baseline $19.5 \%$ reported susceptibility to cigarettes post-ASPIRE, $8.6 \%$ to e-cigarettes, $13.6 \%$ to smokeless tobacco, and $12.3 \%$ to hookah. This study was powered to detect statistical differences in knowledge. Due to insufficient sample size, statistically significant effects were not detected.

A total of 47 of 103 participants provided comments about their experience with ASPIRE. Fifty-five percent (26/47) provided positive responses. Examples include:

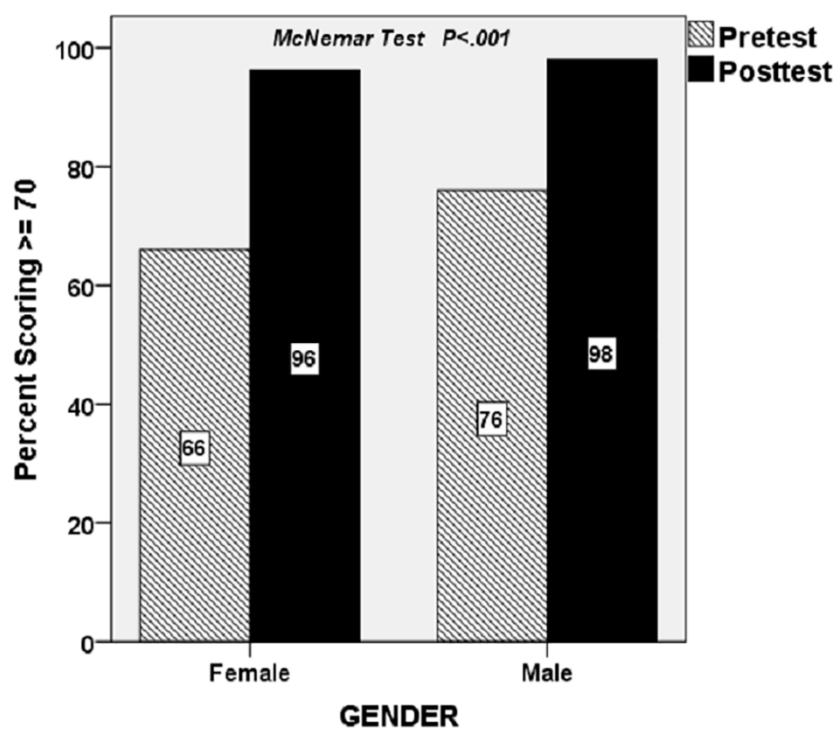

Fig. 1 Pre- to postexposure change in knowledge. 
Table 2 Baseline tobacco and nicotine product use

\begin{tabular}{|l|l|l|}
\hline Tobacco use & \multicolumn{2}{l|}{ (Number of participants $=103)$} \\
\cline { 2 - 3 } & $n$ & (\%) \\
\hline Ever smoked a cigarette? & 19 & 18.5 \\
Smoked in the last 30 days? & 11 & 10.7 \\
\hline Ever used smokeless tobacco? Used smokeless tobacco in last 30 days? & 12 & 11.7 \\
\hline Ever used an electronic cigarette? & 3 & 2.9 \\
\hline Used electronic cigarette in last 30 days? & 12 & 11.7 \\
\hline Ever used a hookah? & 5 & 4.9 \\
Used hookah in last 30 days? & 18 & 17.5 \\
\hline Ever used any tobacco product? & 9 & 8.7 \\
Used a tobacco product in last 30 days? & 35 & 34.0 \\
\hline
\end{tabular}

Table 3 Nonusers susceptibility to tobacco use by gender

\begin{tabular}{|l|l|l|l|l|l|}
\hline \multirow{2}{*}{ Baseline nonusers } & \multicolumn{4}{|c|}{ Nonusers susceptibility } & \multirow{2}{*}{-Value } \\
\cline { 2 - 5 } & \multicolumn{2}{|c|}{ Males } & $\begin{array}{l}\text { Percent } \\
\text { susceptible }\end{array}$ & $n$ & $\begin{array}{l}\text { Percent } \\
\text { susceptible }\end{array}$ \\
\cline { 2 - 6 } & $n$ & 27.3 & 50 & 12.0 & 0.071 \\
\hline Cigarettes $(n=94)$ & 44 & 10.9 & 50 & 8.0 & 0.773 \\
\hline E-cigarettes $(n=96)$ & 46 & 15.9 & 55 & 16.4 & 1.000 \\
\hline $\begin{array}{l}\text { Smokeless tobacco }(n= \\
99)\end{array}$ & 44 & 48 & 12.5 & 1.000 \\
\hline $\begin{array}{l}\text { Hookah } \\
(n=92)\end{array}$ & 44 & 11.4 & & & \\
\hline
\end{tabular}

Table 4 Cultural acceptance of ASPIRE on a scale of 1 to 5

\begin{tabular}{|l|l|}
\hline Cultural acceptance & $\begin{array}{l}\text { Mean (SD) } \\
\text { scale of } \\
1 \text { to } 5\end{array}$ \\
\hline $\begin{array}{l}\text { ASPIRE is culturally appropriate for young } \\
\text { adults in India. }\end{array}$ & $4.1(1.1)$ \\
\hline $\begin{array}{l}\text { An adapted version of ASPIRE targeted towards } \\
\text { Indian youth will be more acceptable. }\end{array}$ & $4.1(1.1)$ \\
\hline
\end{tabular}

Abbreviations: ASPIRE, A Smoking Prevention Interactive Experience; $\mathrm{SD}$, standard deviation.

Table 5 Postexposure to ASPIRE: motivational appeal and educational value of ASPIRE

\begin{tabular}{|l|l|}
\hline Question & $\begin{array}{l}\text { \% Responding } \\
\text { "Yes" } \\
\text { (total = 103) }\end{array}$ \\
\hline $\begin{array}{l}\text { 1) Have you learned new facts about the } \\
\text { risks associated with tobacco use? }\end{array}$ & $100 \%$ \\
\hline $\begin{array}{l}\text { 2) Did the ASPIRE program influence your } \\
\text { decision not to use tobacco in the future? }\end{array}$ & $99 \%$ \\
\hline $\begin{array}{l}\text { 3) Do you have a greater understanding of } \\
\text { how tobacco use affects your health, the } \\
\text { health of your family and friends? }\end{array}$ & $98 \%$ \\
\hline $\begin{array}{l}\text { 4) Would you recommend the ASPIRE pro- } \\
\text { gram to a friend or family member? }\end{array}$ & $95 \%$ \\
\hline
\end{tabular}

Abbreviation: ASPIRE, A Smoking Prevention Interactive Experience.
"ASPIRE made me feel that tobacco is very harmful." "ASPIRE should be spread everywhere so that people get to know things about smoking."

Although most participants agreed that ASPIRE was culturally relevant for an Indian audience, 14 of 47 participants provided constructive criticism about its' cultural relevance. Examples include: "ASPIRE should narrate an Indian child student story."

Seven of 47 participants gave negative comments. Most of the negative comments were from participants who felt that ASPIRE was too long and time consuming. Examples include:

"ASPIRE made me feel that tobacco is very harmful but the levels and scenes are very long and time consuming."

\section{Discussion}

This study results support that ASPIRE as a web-based multimedia smoking prevention program is likely to be a very useful tool to decrease smoking initiation among young adults in India similarly to other web-based interventions implemented in the United State and Western Europe. ${ }^{10,18}$ Although ASPIRE is in the process of being tested in Western countries, it is also tested by some low- to middle-income countries and found effective and efficient tool reducing smoking initiation in youth. ${ }^{13}$ Results of present preliminary study are consistent with the reports of ASPIRE impact elsewhere. 
Table 6 Participant advocacy $(n=103)$

\begin{tabular}{|c|c|}
\hline & $\begin{array}{l}\text { Responding } \\
\text { "Yes" } \\
n(\%)\end{array}$ \\
\hline $\begin{array}{l}\text { Do any of your close family members or } \\
\text { friends use tobacco? }\end{array}$ & $56(54 \%)$ \\
\hline $\begin{array}{l}\text { Have you ever tried to help them } \\
\text { quit? }\end{array}$ & 45 (80\%) \\
\hline \multirow[t]{2}{*}{$\begin{array}{l}\text { Will you recommend ASPIRE to } \\
\text { them? }\end{array}$} & 48 (86\%) \\
\hline & $\begin{array}{l}n(\%) \text { responding } 4 \\
\text { or higher }\end{array}$ \\
\hline $\begin{array}{l}\text { On a scale of } 1 \text { (Not At All) to } 5 \text { (Very } \\
\text { Much) how concerned are you about } \\
\text { their tobacco use? }\end{array}$ & 40 (72\%) \\
\hline
\end{tabular}

Abbreviation: ASPIRE, A Smoking Prevention Interactive Experience.

Of particular interest, the results are pertinent to the cognitive susceptibility to smoking that is a universally recognized and established measure and the strongest predictor of tobacco use among youth. ${ }^{19}$ Males were more susceptible to cigarette smoking compared to females that are conflicting to the literature, ${ }^{15}$ although susceptibility to other tobacco products was similar between males and females. Importantly, exposure to ASPIRE was able to significantly reduce the susceptibility to various tobacco products among the study participants. That, in turn, may signify the program's ability to reduce initiation of multiple nicotine and tobacco products' use in the future.

Majority of participants felt that ASPIRE was culturally appropriate for young adults in India but an adapted version targeted towards Indian youth would be more acceptable. In the present preliminary study, the majority of ASPIRE participants reported an increased knowledge of tobacco hazards, an intention to adopt a tobacco-free lifestyle, and a willingness to share ASPIRE with others. Students who completed ASPIRE were asked if they had close family or friends who used tobacco and approximately 54\% responded "Yes." The majority responded high concern and desire to help. These findings render ASPIRE a highly promising educational tool aimed at substantial reduction of the use of tobacco products in India.

After exposure of ASPIRE curriculum, there was a significant increase in participants who scored $70 \%$ or higher on posttest knowledge about the health, environmental, and financial consequences of using tobacco and nicotine products. Pre- to postintervention knowledge increased from $70 \%$ who scored above $70 \%$ at pretest to $97 \%$ who scored $70 \%$ or higher at posttest. ${ }^{10-12}$ Interestingly, this exceptionally high percentage at postexposure is comparable with those obtained by the MD Anderson investigators among ASPIRE participants in the United States. ${ }^{20}$ Approximately 45\% participants provided comments about their experience with ASPIRE. Some of the positive comments are "ASPIRE made me feel that tobacco is very harmful" and "The ASPIRE program should be taken by not only a certain youths but also almost every youths in the country." Relatively small percentage (15\%) of the participants gave negative comments on ASPIRE and it was about program length and number of levels. This is to be expected in preliminary studies and, typically, this percentage drops substantially after the necessary adjustments and cultural adaptation of the program has been completed.

\section{Limitations}

The study was limited by few factors such as small sample size and convenience sample; therefore, generalizability of the results is obviously an issue. Also,

1. ASPIRE 2.0 was designed and tested primarily among middle- and high-school students in the United States. This was a first attempt to test an English version of ASPIRE among college students in India with a different cultural upbringing and language. Although the majority of students had a good command of the English language, some students would have preferred a culturally adapted version of ASPIRE. The program is currently planned to be translated and culturally adapted for Indian users.

2. Students reported a low prevalence of cigarette smoking and smokeless tobacco. Self-reported smoking status was not verified by biological testing. Indian students are less likely to report smoking behavior due to parental and societal factors. Although this is a limitation, the target audience represents young adults who are more likely to provide accurate self-reported smoking status than their teenage counterparts.

3. The study was conducted in a single city in India with majority of students of Hindu origin.

Table 7 Change in cognitive susceptibility to tobacco use (pre- to postexposure to ASPIRE)

\begin{tabular}{|c|c|c|c|c|c|}
\hline \multirow{2}{*}{$\begin{array}{l}\text { Total nonusers of } \\
\text { products }\end{array}$} & \multicolumn{2}{|c|}{ Preexposure to ASPIRE } & \multicolumn{2}{|c|}{ Postexposure to ASPIRE } & \multirow[t]{2}{*}{ McNemar's p-Value } \\
\hline & $\begin{array}{l}\text { Number } \\
\text { susceptible }\end{array}$ & (\%) & $\begin{array}{l}\text { Number } \\
\text { susceptible }\end{array}$ & $\begin{array}{l}\text { \% Reduction in } \\
\text { susceptibility }\end{array}$ & \\
\hline Cigarettes $(n=88)$ & 16 & 18.2 & 1 & 90.9 & 0.424 \\
\hline e-Cigarettes $(n=90)$ & 9 & 10.0 & 2 & 77.8 & 1.000 \\
\hline $\begin{array}{l}\text { Smokeless tobacco ( } n \\
=90)\end{array}$ & 13 & 14.4 & 2 & 77.8 & 0.481 \\
\hline Hookah $(n=81)$ & 9 & 11.1 & 0 & 100 & 1.000 \\
\hline
\end{tabular}

Abbreviation: ASPIRE, A Smoking Prevention Interactive Experience. 
Overall, despite of the aforementioned limitations, our preliminary study highlighted the feasibility of a web-based smoking prevention program among Indian urban school settings. Also, there are several prominent potencies in this study which concludes that there is need for program like ASPIRE in India to prevent smoking which is having increased trend especially in young females and causes multiple deleterious sequelae.

\section{Conclusion}

Online approach provides innovative opportunities for engaging young audiences in India in learning about nicotine and tobacco behaviors. Web-based programs easily draw youth's attention to delivery education especially if multimedia features are involved in it. ASPIRE is a multimedia interactive curriculum for nicotine and tobacco use prevention capable of increasing the knowledge about tobacco products' hazards and reducing susceptibility to these products. ASPIRE program, developed and tested in the United States, has a considerable potential to substantially reduce nicotine and tobacco use initiation among Indian youth.

\section{Data Archiving}

Data supporting the results reported in the article is available upon request.

\section{Statement of Ethics}

This study was approved by an independent review board (Ref. No: Res/SCM/29/2018/51). We certify that all applicable institutional and governmental regulations concerning the ethical use of survey data were followed during the course of this research study.

\section{Acknowledgements}

The authors would like to thank Department of Research, Rajiv Gandhi Cancer Institute and Research Centre, New Delhi, for supporting this study. The authors have no other relevant affiliations or financial involvement with any organization or entity with a financial interest in or financial conflict with the subject matter or materials discussed in the manuscript apart from those disclosed. No writing assistance was utilized in the production of this manuscript.

\section{Conflict of Interest}

The authors have nothing to declare.

\section{References}

1 Chandrupatla SG, Tavares M, Natto ZS. Tobacco use and effects of professional advice on smoking cessation among youth in India. Asian Pac J Cancer Prev 2017;18(7):1861-1867

2 Mishra S, Joseph RA, Gupta PC, et al. Trends in bidi and cigarette smoking in India from 1998 to 2015, by age, gender and education. BMJ Glob Health 2016;1(1):e000005

3 Nagarajan R, Thakur A. Smoking dips 10\% in 2 years in India but women smokers up sharply. https://timesofindia.indiatimes.com/. December 28, 2015
4 Bold KW, Krishnan-Sarin S, Stoney CM. E-cigarette use as a potential cardiovascular disease risk behavior. Am Psychol 2018;73(8):955-967

5 GBD 2015 Tobacco Collaborators. Smoking prevalence and attributable disease burden in 195 countries and territories, 1990-2015: a systematic analysis from the Global Burden of Disease Study 2015. Lancet Lond Engl 2017;389(10082): 1885-1906

6 Sinha DN, Reddy KS, Rahman K, Warren CW, Jones NR, Asma S. Linking Global Youth Tobacco Survey (GYTS) data to the WHO framework convention on tobacco control: the case for India. Indian J Public Health 2006;50(2):76-89

7 Institute of Medicine, Committee on Preventing Nicotine Addiction in Children and Youths. Growing up Tobacco Free - NCBI Bookshelf. National Academies Press (US); 1994. https://www.ncbi.nlm.nih.gov/books/NBK236763/. Accessed March 5, 2021

8 Khandal S, Kar S, Rastogi S, Rastogi S. Why people smoke? - an empirical study in Bangalore. Int J Res Humanit Arts Lit 2019;7(4):419-426

9 Pradhan PMS, Niraula SR, Ghimire A, Singh SB, Pokharel PK. Tobacco use and associated factors among adolescent students in Dharan, Eastern Nepal: a cross-sectional questionnaire survey. BMJ Open 2013;3(2):e002123

10 Prokhorov AV, Kelder SH, Shegog R, et al. Impact of A Smoking Prevention Interactive Experience (ASPIRE), an interactive, multimedia smoking prevention and cessation curriculum for culturally diverse high-school students. Nicotine Tob Res 2008;10(9):1477-1485

11 Prokhorov AV, Marani SK, Calabro KS, Ford KH. Theory and Technology-Driven Educational Curricula Addressing Tobacco Use. In: Proceedings of the 4th World Conference on Educational Sciences. Vol 46. Procedia - Social and Behavioral Sciences; 2012

12 Thomas RE, McLellan J, Perera R. School-based programmes for preventing smoking. Cochrane Database Syst Rev 2013; (4):CD00129310.1002/14651858.CD001293.pub3

13 Nădăşan V, Foley KL, Pénzes M, et al. The Short-term Effects of ASPIRA: a web-based, multimedia smoking prevention program for adolescents in Romania: a cluster randomized trial. Nicotine Tob Res 2017;19(8):908-915

14 Cohen J, Statistical Power Analysis for the Behavioral Sciences (2nd ed.). Routledge. 1988. Available at https://doi. org/10.4324/9780203771587

15 Khalil GE, Calabro KS, Prokhorov AV. Development and initial testing of the brief adolescent smoking curiosity scale (ASCOS) Addict Behav 2018;78:67-73

16 Pierce J, Farkas A, Evans N, Gilpin E. An improved surveillance measure for adolescent smoking. Tob Control 1995;4:S47-S56

17 Pierce JP, Choi WS, Gilpin EA, Farkas AJ, Merritt RK. Validation of susceptibility as a predictor of which adolescents take up smoking in the United States. Health Psychol 1996;15(5):355-361

18 de Josselin de Jong S, Candel M, Segaar D, Cremers H-P, de Vries $H$. Efficacy of a Web-based computer-tailored smoking prevention intervention for Dutch adolescents: randomized controlled trial. J Med Internet Res 2014;16(3): e8210.2196/jmir.2469

19 Gritz ER, Prokhorov AV, Hudmon KS, et al. Predictors of susceptibility to smoking and ever smoking: a longitudinal study in a triethnic sample of adolescents. Nicotine Tob Res 2003;5(4):493-506

20 Prokhorov AV, Kelder SH, Shegog R, et al. Project ASPIRE: an Interactive, Multimedia Smoking Prevention and Cessation curriculum for culturally diverse high school students. Subst Use Misuse 2010;45(6):983-1006. doi: 10.3109/10826080903038050. 